wine and the dregs from the oil presses were other preventive measures. Greasebands were fixed on the vines, and indeed are still used in Turkey.

No doubt the prevalence of pests and diseases, and the lack of knowledge of how to destroy or cure them, was a factor, among others, that kept yields at a low level for a thousand years or more.

Mr. Ordish proceeded to a discussion of the work of the sixteenth- and seventeenth-century botanists, more particularly that of Thomas Mouffett and Topsell. He said that Worlidge in 1669 had set out a method of dealing with hop mildew that would effectively control one type. The belief in the spontaneous generation of bugs, lice and other insects "out of corruption" was widely held by writers of that date, and was not disposed of until later scientists had shown that these pests were born out of eggs. New material had become available in the eighteenth century, and Richard Weston and others suggested the use of tobacco dust, spraying with a nicotine solution, and fumigating with tobacco smoke. Steeps of brine and urine had continued to be used to control cereal rusts, but there was some dispute about their efficacy. Some remarkable randomized experiments were made by Tilly in France about 1750 to test controls.

Necessarily, Mr. Ordish's paper was an outline of a vast subject, and, as was then said, it is to be hoped that he will make and publish an exhaustive study of the subject. The only existing treatise is a very brief American publication.

Dr. Bennett traced the development of commercial market gardening from the sixteenth to the nineteenth century. Before 1500 he thinks there was little. The use of vegetables is said to have declined. between the eleventh and the sixteenth centuries, and to have been revived only with the new methods of cultivation introduced to Great Britain by French and Dutch refugees from religious persecution. It is, however, a little difficult to accept this conclusion, because, if it is true, some other food must have taken the place of the onion, garlic, leek, cabbage, peas and beans, worts and other herbs that all went into the pottage commonly consumed by the gener- ality of the people. Be that as it may, Dr. Bennett made it quite clear that there was a great extension of market gardening in the sixteenth century. The refugees settled in the Sandwich area and elsewhere in Kent, around Norwich, and eventually in the immediate environs of London, where a part of Covent Garden was set aside for a vegetable and fruit market held three days a week. The Worshipful Company of Gardeners was organized by the growers to exercise control over malpractices and to look after their interests. From this time market gardening increased in importance, especially in the nineteenth century, when the growth of population in larg $\theta$ aggregations, some rise in the standard of living, and chang 35 in dietetic taste led to an immensely increased demand for fruit and vegetables.

Mr. Hobbis indicated no such decline in the use of soft fruits during the Middle Ages as there may have been in vegetables and herbs. Strawberries, raspberries and gooseberries were known to our remote ancestors, but the raspberries were not very well liked until the sixteenth century. They were thought sour. Red currants were then regarded as a small kind of red gooseberry. From such small beginnings a very large soft-fruit growing industry had developed by the nineteenth century, and it expanded widely during that century, though it had not then spread to the eastern counties. The two wars had a bad effect, but the soft-fruit growing industry under modern influences-factory jam-making, canning, deep freezing, and so on-is reviving, while the results of research are providing growers with advantages unknown to their predecessors.

Such subjects are not simple, and it is difficult to make a summary of all the important points raised in these two lectures and the discussion that followed them. All three lecturers demonstrated that there are large areas in the history of agriculture and horticulture that still require exploration.

The headquarters of the British Agricultural History Society have now been moved to the Department of Agriculture, Parks Road, Oxford, and anyone interested should make inquiries of the Hon. Secretary at that address. G. E. FUSSELL

\title{
GELATINE AND GLUE
}

A $T$ the fourteenth meeting of the Research Panel of the British Gelatine and Glue Research Association, held on December 12, Dr. S. M. Partridge (Low Temperature Research Station) took the chair for the morning session and Mr. S. G. Hudson (Richard Hodgson and Sons, Ltd.) for the afternoon session. The first paper was by Mr. G. Russell (Ilford, Ltd.) with the title "Chemically Distinct Major Components of Gelatin"1. He outlined previous views on the level of impurities (other than inorganic ions) in high-grade gelatines. Methods such as heat cosgulation, or adsorption on charcoal, suggest a protein impurity-level of not more than 0.5 per cent. In an attempt to separate these impurities from gelatin, experiments were carried out, in which chromatographic column technique was applied, using a finely divided form of the resin, 'I.R.C.50'. Elution was effected with a buffer previously used for equilibrating the column, so that the whole operation took place at the same $p H$. Protein in the fractions was estimated, after hydrolysis, by reaction with ninhydrin.
Whereas at $p \mathrm{H} 6$ the whole of the gelatin sample is eluted, giving a curve of concentration against eluant volume with a twin peak, at $p H \mathbf{H} 5 \cdot 5$ only a portion of the sample (15 per cent) is eluted, the remainder (85 per cent) being firmly adsorbed on the resin. The latter fraction can be removed by raising the $p H$. Paper chromatograms show the smaller component to have a higher tyrosine content than ordinary gelatin, no detectable hydroxyproline, and other characteristics giving it an amino-acid composition broadly similar to the serum albumins. The major component is similar to gelatin. Quantitative results for tyrosine, using ultra-violet absorption, show the major component to have zero or only a trace of tyrosine, whereas the minor component has about 3 per cent. Assuming the tyrosine to be entirely present in the minor component, the content of this component in a series of gelatins ranges from 10 to 20 per cent. Mr. Russell considered some of the implications of his work, and a keen discussion showed the interest aroused. Dr. G. R. Tristram (University 
of St. Andrews) reported a separation, presumably of the same two components, on a modified cellulose column. It was clear from many comments that the future course of research on gelatin may be very much modified by Mr. Russell's work.

The second paper, "Some Aspects of Connective Tissue in Relation to Age", by Dr. R. Consden and Dr. P. C. Brown, of the Special Unit for Juvenile Rheumatism of the Canadian Red Cross Memorial Hospital, Maidenhead, discussed the chemical makeup of connective tissue. Recent work, both on collagen and on the polysaccharides of connective tissue, has reverled the complexity of the problems requiring solution. Whereas certain polysaccharides are readily removed by very mild processes, others are so firmly held that their association with the collagen must be very intimate. This applies in particular to the neutral polysaccharides. The course of fibrogenesis was outlined, and the contrast between young tissues, whether in young animals or in freshly formed tissue in wounds, and mature tissues was emphasized The inertness of collagenous tissue was illustrated from Glynn's experiments on embedding dead tissue in living animals to study their rate of destruction. Collagen appears to persist indefinitely, whereas liver or muscle is metabolized fairly quickly. If, however, the collagen is heat-shrunk, it then is attacked fairly rapidly. The collagen of the uterus, which Harkness has studied, shows unusual features in being able to undergo rapid growth during pregnancy and rapid reabsorption at parturition. The increased stability of collagen with age, which can be demonstrated also as an increase in the force to inhibit contraction under thermal shrinkage conditions, is related to greater orientation and crystal. linity. Keech has shown that a greater resistance to collagenase develops. A survey of human collagenous tissue shows that there is a significant increase of shrinkage temperature with age, and older tissue is more resistant than young to the action of hydrogenbond breaking reagents. Uterine collagen has a significantly lower shrinkage temperature than adult collagen from elsewhere.

The third paper, "An Approach to the NonGelatin Constituents of Gelatines and Glues", was given by Mr. A. A. Leach, of the Association staff. Using bone glue as the starting material, it is possible to separate from it a component, present in substantial amount, which partially coagulates at about $p \mathrm{H} 4$ and can be centrifuged off. This component is made up of a complex of lipid, polyseccharide, noncollagenous protein and a gelatin-like substance. The lipid is derived from the bone fat, and the analytical evidence suggests that the polyseccharide and noncollagen protein have their origin in the 'osseomucoid' isolated from compact bone and analysed by Eastoe and Eastoe. It is not certain to what extent the links between gelatin and the complex are formed during processing in bone glue manufacture, or are already present in the tissue. Attempts to separate the gelatin from the complex, using either heat coagulation of the second protein or differential trypsin attack on the gelatin, although partially successful, were not quantitative.

Bone glue from which the complex had boen removed wes fractionated by the alcohol method of Stainsby. It was then shown that the bulk of the non-gelatin components, other than the complex, remain in solution at the end of fractionation. They include substantial amounts of polysaccharide. It must be presumed that a further separation of the 'gelatin-like' fractions into the two components of Russell above would still be possible using the resin column technique. A. G. WARD

\title{
PIGMENTATION OF INTESTINAL MUSCLE IN STEATORRHCA
}

\author{
By Dr. G. AUSTIN GRESHAM and J. G. CRUICKSHANK \\ Department of Pathology, University of Cambridge
}

AND

\section{J. C. VALENTINE \\ Bedford Group Hospitals}

TNTESTINAL biopsy has proved of little value in the diagnosis of idiopathic steatorrhoea. Paulley ${ }^{1}$ has described changes in the mucosa which cannot be regarded as specific.

The object of this communication is to report a hitherto undescribed association between a lipoprotein pigment in intestinal smooth muscle and steatorrhœea.

The material was obtained from necropsies on a variety of intestinal disorders (Table 1). Four of the cases of steatorrhcea were diagnosed in life on the basis of high content of fat in the stool, high proportion of unsplit fat, low serum calcium-lovel and megaloblastic anæmia. The percentage of fat absorbed was found to be abnormally low in three cases, using a 'fat balance' test. In two other cases, in which pigment was found, the diagnosis of steator. rhcea was not confirmed during life. In one of these cases a diagnosis of Whipple's disease ${ }^{2}$ rested upon histological findings alone.
Pieces for histogical examination were fixed in 10 per cent formal-saline or in corrosive formal. Paraffin sections were prepared and stained by Herris's hæmatoxylin and eosin; preliminary treatment with Lugol's iodine and sodium thiosulphate was given to those fixed in corrosive formal.

Those sections which showed pigment in the smooth muscle of the small intestine were stained by histochemical methods. Sections were stained for protein by the tetrazo method of Danielli following the technique described by Dixon. This method detects tyrosine, tryptophan and histidine groups in the protein molecule. The Feulgen method' for deoxyribonucleic acid and pyronin $G^{5}$ for ribonucloic acid were applied. The periodic acid-Schiff method and the permanganate-paraldehyde-fuchsin method 7 were used for detecting carbohydrates. Sudan black was employed for detecting lipids.

The presence of an unusual pigment was suggested in the case of Whipple's disease by a brown coloration 